\title{
KEMAMPUAN MERANCANG DAN MELAKSANAKAN \\ EVALUASI PEMBELAJARAN GURU BAHASA ARAB MTS \\ DI KABUPAEN BANTUL
}

Oleh: Muhamad Fathoni

Dosen STAIMS Yogyakarta

\begin{abstract}
This research shows that: Frist, Arabic teacher pedagogic competence in MTs in designing and learning evaluation in Bantul region, has enough ability. With the value of average is 73 for teachers were certificated and 65 for teachers not certificated yet. Second, $T_{\text {value }}$ less than $T_{\text {table }}(1,469<2,03)$ and the signification standard greater than the signification $0,05(0,005<0,05)$ so $H_{0}$ received, its mean that there is not significant changing test value between teachers certificated and teachers not certificated. From the table of group statistics above, seems that the average of teachers certificaed are 73,42 and teachers that not certificated are 64,69, it mean the average value of teachers that certificated are not greater than the average of teachers certificated yet.
\end{abstract}

\begin{abstract}
Abstrak
Hasil penelitian ini menunjukan bahwa: Pertama, Kompetensi Pedagogik Guru Bahasa Arab MTs dalam Merancang dan Melaksanakan Evaluasi Pembelajaran di Kabupaten Bantul, mumpunyai tingkat kemampuan cukup yaitu dengan nilai ratarata 73 untuk kelompok guru yang sudah sertifikasi dan 65 untuk kelompok guru

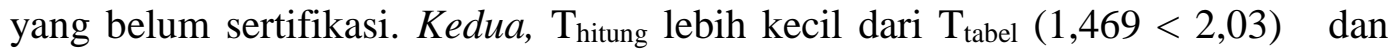
Signifikansinya lebih besar dari signifikansi $0,05(0,005<0,05)$ maka $\mathrm{H}_{0}$ terima, artinya tidak ada perbedaan nilai tes yang signifikan antara kelompok guru yang sudah sertifikasi dengan kelompok guru yang belum sertifikasi. Pada tabel Group statistics diatas terlihat rata-rata (mean) untuk kelompok guru yang sudah sertifikasi adalah 73,42 dan untuk kelompok guru yang belum sertifikasi adalah 64,69 , artinya bahwa nilai rata-rata kelompok guru yang sudah sertifikasi tidak lebih tinggi dari pada rata-rata untuk kelompok guru yang belum sertifikasi.
\end{abstract}

\section{A. PENDAHULUAN}

Salah satu kompetensi yang wajib dimiliki oleh seorang guru adalah kompetensi Pedagogik, dalam Standar Nasional Pendidikan, penjelasan Pasal 28 ayat (3) butir (a) dikakatakan bahwa kompetensi pedagogik adalah kompetensi mengelola pembelajaran peserta didik yang meliputi pemahaman terhadap peserta didik, perancangan dan pelaksanaan 
pembelajaran, evaluasi hasil belajar, dan pengembangan peserta didik untuk mengaktualisasikan berbagai potensi yang dimilikinya. ${ }^{1}$

Oleh karena itu, seharusnya semua guru Bahasa Arab sudah memiliki kompetensi Pedagogik yang baik dalam merancang dan melaksanakan evaluasi pembelajaran, sehingga dapat meningkatkan hasil belajar siswa, namun pada kenyataannya dari hasil Ujian Akhir Madrasah Berstandar Nasional (UAMBN) pada tahun ajaran 2011/2012 nilai mata pelajaran Bahasa Arab ditingkat Madrasah Tsanawaiyah se-Kabupaten Bantul yang berjumlah 22 sekolah, masih terkesan rendah yaitu nilai tertinggi 7,58, nilai terendah 3,10 dan nilai rata-ratanya adalah 5,31, sedangkan pada tahun ajaran 2012/2013 nilai UAMBN tertinggi 7,39, nilai terendah 2,57 dan nilai rataratanya 4,26. ${ }^{2}$ Hasil UAMBN yang masih rendah dan menurun tersebut dimungkinkan terjadi karena adanya beberapa faktor, diantaranya siswa yang kurang maksimal dalam belajar, guru yang kurang professional dalam mengajar, instrument evaluasi yang kurang tepat dan lain sebagainya.

Dari latar belakang dan permasalah yang telah dikemukakan di atas, maka peneliti berkeinginan untuk mengadakan penelitian lebih lanjut terhadap kemapuan pedagogik guru bahasa Arab dalam merancang dan melaksanakan evaluasi di Madrasah Tsanawiyah se-Kabupaten Bantul, hal itu bertujuan untuk mengetahui seberapa besar kemapuan pedagogik guru bahasa Arab dalam merancang dan melaksanakan evaluasi di Madrasah Tsanawiyah se-Kabupaten Bantul, dan juga untuk mengetahui adakah perbedaan kemapuan pedagogik guru bahasa Arab dalam merancang dan melaksanakan evaluasi anatara guru yang sudah sertifikasi dan yang belum sertifikasi, yang nantinya akan peneliti bahas dalam tesis yang berjudul

${ }^{1}$ Peraturan Pemerintah Republik Indonesia No. 19 Tahun 2005 tentang Standar Nasional Pendidikan http://akademik.um.ac.id/wp-content/uploads/2009/09/PP-NOMOR-19TAHUN-2005.doc. Diakses 18 November 2013

${ }^{2}$ Hasil Ujian Akhir Madrasah Berstandar Nasional (UAMBN) Tahun Ajaran 2011 2012 dan Tahun Ajaran 2012-2013, http://yogyakarta.kemenag.go.id. Diakses 04 November 2013 
"Kompetensi Pedagogik Guru Bahasa Arab MTs dalam Merancang dan Melaksanakan Evaluasi Pembelajaran di Kabupaten Bantul”.

\section{B. LANDASAN TEORI}

\section{Pengertian Kompetensi Pedagogik Guru}

Kata kompetensi dalam Kamus Besar Bahasa Indonesia, kompetensi diartikan kewenangan (kekuasaan) untuk menentukan (memutuskan sesuatu). Kompeten artinya orang yang cakap, (mengetahui), berwenang, berkuasa (memutuskan dan menentukan) sesuatu. Sedangkan kaitannya dengan profesi, W. Rober houston, sebagaimana yang dikutip oleh Syaiful Bahri Djamarah menyatakan "competence ordinarily isdefined as edacuacy for a task possession of require knowledge, skill andabilities", yang maksudnya kompetensi sebagai suatu tugas yang memadai, atau pemilikan pengetahuan, keterampilan yang dituntut oleh jabatan seseorang. ${ }^{3}$ Sementara itu, Moh. Uzer Usman, menyatakan kompetensi guru merupakan "kemampuan seorang guru dalam melaksanakan kewajiban-kewajiban serta bertanggungjawab dan layak". ${ }^{4}$

Kata pedagogik berasal dari istilah bahasa Yunani "paedos" (anak) dan "agogus" (membimbing). Jadi "pedagogik" atau "ilmu mendidik" mempunyai makna sebagai satu kiat dan ilmu untuk membimbing dan mengembangkan anak ke arah kedewasaan. ${ }^{5}$

\footnotetext{
${ }^{3}$ Syaiful Bahri Djamarah, Prestasi Belajar dan Kompetensi Guru (Surabaya: UsahaNasional, 1994), hlm, 33

${ }^{4}$ Moh. Uzer Usman, Menjadi Guru Profesional, (bandung: Remaja Rosda Karya, 1992),hlm, 14

${ }^{5}$ Uyo Sadullah, Pedagogik (Ilmu Mendidik) (Bandung:Alfabeta, 2011), hlm.2.
} 
Di dalam penjelasan Undang-Undang nomor 14 tahun 2005 tentang Guru dan Dosen, yang di maksud dengan kompetensi pedagogik adalah kemampuan mengelola pembelajaran peserta didik. ${ }^{6}$

Dalam Standar Nasional Pendidikan, penjelasan Pasal 28 ayat (3) butir (a) dikemukakan bahwa kompetensi pedagogik adalah kemampuan mengelolah pembelajaran peserta didik yang meliputi pemahaman terhadap peserta didik, perancangan dan pelaksanaan pembelajaran, evaluasi hasil belajar, dan pengembangan peserta didik untuk mengaktualisasikan berbagai potensi yang dimilikinya. ${ }^{7}$

\section{Evaluasi Pembelajaran}

\section{a. Pengertian Evaluasi Pembelajaran}

Evaluasi berasal dari kata evaluation (bahasa inggris) yang artinya penilaian atau penaksiran. ${ }^{8}$ Kata tersebut diserap kedalam istilah bahasa indonesia menjadi "evaluasi". Menurut bahasa penilaian diartikan sebagai proses mementukan nilai suatu objek. ${ }^{9}$ Sedangkan menurut istilah evaluasi merupakan suatu proses merencanakan, memperoleh, dan menyediakan informasi yang sangat diperlukan untuk membuat alternatif-alternatif keputusan. ${ }^{10}$

Peraturan Pemerintah RI No. 19 Tahun 2005 menyatakan bahwa evaluasi adalah kegiatan pengendalian, penjaminan, dan penetapan mutu pendidikan terhadap berbagai komponen pendidikan

${ }^{6}$ E. Mulyasa, Standar Kompetensi dan Sertifikasi Guru (Bandung: Remaja Rosdakarya, 2007), hlm. 75.

${ }^{7}$ Peraturan Pemerintah Republik Indonesia No. 19 Tahun 2005 tentang Standar Nasional Pendidikan http://akademik.um.ac.id/wp-content/uploads/2009/09/PPNOMOR-19-TAHUN-2005.doc. Diakses 18 November 2013

8 John M. Echols dan Hasan Shadily, Kamus Inggris Indonesia, (Jakarta: Gramedia,1996), hlm. 220.

9 Nana Sudjana, Penilaian Hasil Proses Belajar Mengajar, (Bandung: PT Remaja Rosdakarya, 1991), hlm. 3

10 Ngalim Purwanto, Prinsip-Prinsip dan Teknik Evaluasi Pengajaran, (Bandung: PT Remaja Rosdakarya, 2006), hlm. 3 
pada setiap jalur, jenjang, dan jenis pendidikan sebagai bentuk pertanggungjawaban penyelenggaraan pendidikan. ${ }^{11}$

Dari pengertian di atas, dapat disimpulkan bahwa evaluasi pembelajaran adalah proses sistematik untuk menentukan atau membuat keputusan sampai sejauh mana tujuan-tujuan pembelajaran telah dicapai oleh peserta didik.

\section{b. Bentuk Evaluasi Pembelajaran}

Berdasarkan waktu dan fungsinya evaluasi dapat diklasifikasikan menjadi empat macam, yakni: ${ }^{12}$

1) Diagnostik (diagnostic test)

2) Tes Formatif (formative test)

3) Tes Sumatif (summative test)

4) Tes penempatan (placement test)

\section{c. Prinsip-prinsip Evaluasi Pembelajaran}

1) Prinsip Berkesinambungan (continuity).

2) Prinsip Menyeluruh (comprehensive).

3) Berorientasi pada Indikator Pencapaian.

4) Prinsip Validitas (validity) dan Reliabilitas (reability).

5) Obyektifmitas (objectivities)

6) Praktikabilitas (Practicability).

\section{d. Tujuan dan Fungsi Evaluasi Pembelajaran}

Tujuan utama melakukan evaluasi dalam proses belajar mengajar adalah untuk mendapatkan informasi yang akurat mengenai tingkat pencapaian tujuan instruksional oleh peserta didik sehingga dapat diupayakan tindak lanjutnya. ${ }^{13}$

${ }^{11}$ Depdiknas RI, Standar Nasional Pendidikan (PP RI No. 19 Tahun 2005), (Jakarta: Sinar Grafika, 2006), hlm.4.

${ }^{12}$ Daryanto, Evaluasi Pendidikan, (Jakarta: PT Rineka Cipta, 2001), cet. II hlm. $12-14$.

13 Suke Silverius, Evaluasi Hasil Belajar dan Umpan Balik, (Jakarta: PT Grasindo, 1991), hlm. 9. 


\section{e. Pendekatan Tes Bahasa}

1) Tes Diskret.

2) Tes Intregratif.

3) Tes Prakmatik.

\section{f. Penyusunan Tes Bahasa Arab}

Tes yang baik adalah yang telah memenuhi karaktristik tes yang baik, yaitu valid, reliable, dan praktis.

\section{g. Analisis Butir Soal dalam Tes bahasa}

Analisis butir soal dalam tes bahasa bertujuan untuk mengungkapkan ciri-ciri, mutu butir tes, serta hal-hal yang berkaiatan dengan pengembangan, penelitian, dan penggunaan tes yang telah baik dan perlu dipertahankan. ${ }^{14}$

Adapun analisis yang dilakukan yaitu, sebagai berikut: ${ }^{15}$

1) Analisis tikat kesulitan.

2) Analisis daya pembeda

3) Analisis butir soal esai

4) Analisis pengecoh

\section{PEMBAHASAN DAN HASI PENELITIAN}

Berikut ini akan peneliti sajikan data Guru Bahasa Arab MTs di Kabupaten Bantul yang dijadikan obyek penelitian, yaitu tentang nama dan tempat tugas, usia, latar belakang pendidikan, dan status kepegawaian. Keseluruhan dapat peneliti peroleh dari pendataan yang peneliti lakukan. Berikut ini peneliti sajikan data tersebut:

\footnotetext{
${ }^{14}$ Ibid., hlm. 128

15 Sri Wahyuni dan Abd. Syukur Ibrahim, Asesmen Pembelajaran Bahasa, (Bandung: PT. Refika Aditama, 2012), hlm. 129-141
} 


\section{Daftar Guru Bahsa Arab MTs di Kabupaten Bantul}

Tabel. 1

Data Guru Bahasa Arab Madrasah Tsanawiyah

di Kabupaten Bantul

\begin{tabular}{|c|c|c|c|c|c|}
\hline \multirow{2}{*}{ No } & \multirow{2}{*}{ Nama Guru } & \multirow{2}{*}{ Tempat Tugas } & \multirow{2}{*}{ Sertifikasi } & \multicolumn{2}{|c|}{$\begin{array}{c}\text { Pendidikan } \\
\text { Terakhir }\end{array}$} \\
\hline & & & & Jurusan & Jenjang \\
\hline 1 & $\begin{array}{l}\text { Drs. Achmad } \\
\text { Charis Munandar }\end{array}$ & $\begin{array}{l}\text { MTsN } \\
\text { Wonokromo }\end{array}$ & Sudah & $\mathrm{TH}$ & $\mathrm{S} 1$ \\
\hline 2 & $\begin{array}{l}\text { Ahmad Daris } \\
\text { Mustofa, M.S.I }\end{array}$ & $\begin{array}{l}\text { MTsN } \\
\text { Wonokromo }\end{array}$ & Sudah & MKPI & $\mathrm{S} 2$ \\
\hline 3 & Drs. Amaroni & $\begin{array}{l}\text { MTs Ali } \\
\text { Maksum }\end{array}$ & Sudah & BAR & $\mathrm{S} 1$ \\
\hline 4 & $\begin{array}{l}\text { Anis Suryani, } \\
\text { S.Ag }\end{array}$ & $\begin{array}{l}\text { MTsN Bantul } \\
\text { Kota }\end{array}$ & Sudah & BAR & $\mathrm{S} 1$ \\
\hline 5 & Asfari, S.Ag & MTsN Lab UIN & Sudah & MJ & $\mathrm{S} 1$ \\
\hline 6 & $\begin{array}{l}\text { Asna Fitriani, } \\
\text { S.Pd.I }\end{array}$ & MTs Al Falaah & Belum & PAI & $\mathrm{S} 1$ \\
\hline 7 & Atik Malihah M & $\begin{array}{l}\text { MTs Ibnu } \\
\text { Qoyyim Putra }\end{array}$ & Belum & PAI & $\mathrm{S} 1$ \\
\hline 8 & $\begin{array}{l}\text { Hafidl Hidayat, } \\
\text { S.Fil.I }\end{array}$ & MTs Muh. Pepe & Belum & $\mathrm{AF}$ & $\mathrm{S} 1$ \\
\hline 9 & Haryanto, S.Pd.I & $\begin{array}{l}\text { MTs Ma'had } \\
\text { Islamy }\end{array}$ & Belum & PAI & $\mathrm{S} 1$ \\
\hline 10 & Hendriana Wijaya & $\begin{array}{l}\text { MTs Ibnu } \\
\text { Qoyyim Putra }\end{array}$ & Belum & - & MA \\
\hline 11 & $\begin{array}{l}\text { Heru Sukamto, } \\
\text { A.Md }\end{array}$ & $\begin{array}{l}\text { MTs } \\
\text { Muh.Sanden }\end{array}$ & Belum & MP & D3 \\
\hline 12 & $\begin{array}{l}\text { Imroatul Azizah, } \\
\text { S.Ag }\end{array}$ & $\begin{array}{l}\text { MTs Ali } \\
\text { Maksum }\end{array}$ & Sudah & PBA & $\mathrm{S} 1$ \\
\hline 13 & Dra. Istriyanti & MTsN Griloyo & Sudah & BAR & $\mathrm{S} 1$ \\
\hline 14 & $\begin{array}{l}\text { Janatul } \\
\text { Mutmainah, S.S }\end{array}$ & MTs Al Mahalli & Belum & BSA & $\mathrm{S} 1$ \\
\hline 15 & Jarnawi, S.Ag & MTs Muh.Pepe & Sudah & PA & $\mathrm{S} 1$ \\
\hline 16 & $\begin{array}{l}\text { Jumanudin, } \\
\text { M.Pd.I }\end{array}$ & MTsN Pundong & Sudah & PI & $\mathrm{S} 2$ \\
\hline 17 & Kamiludin, S.Pd.I & $\begin{array}{l}\text { MTs Muh. } \\
\text { Kasihan }\end{array}$ & Sudah & PBA & $\mathrm{S} 1$ \\
\hline 18 & $\begin{array}{l}\text { Laila Maftuhah, } \\
\text { S.Pd.I }\end{array}$ & $\begin{array}{l}\text { MTs Hasyim } \\
\text { Asy'ari }\end{array}$ & Belum & PAI & $\mathrm{S} 1$ \\
\hline 19 & $\begin{array}{l}\text { M. Khoeron, } \\
\text { S.Ag }\end{array}$ & MTsN Dlingo & Sudah & BAR & $\mathrm{S} 1$ \\
\hline
\end{tabular}




\begin{tabular}{|c|c|c|c|c|c|}
\hline 20 & Mahrus, S.Pd.I & $\begin{array}{l}\text { MTs Ma'had } \\
\text { An Nur }\end{array}$ & Belum & PAI & $\mathrm{S} 1$ \\
\hline 21 & Marwan Hamid & $\begin{array}{l}\text { MTs Al Falaah } \\
\text { Pandak }\end{array}$ & Sudah & BAR & $\mathrm{S} 1$ \\
\hline 22 & $\begin{array}{l}\text { Miftakhul Munir, } \\
\text { S.Ag }\end{array}$ & MTsN Griloyo & Sudah & BAR & $\mathrm{S} 1$ \\
\hline 23 & $\begin{array}{l}\text { Muhammad } \\
\text { Jawis, S.S }\end{array}$ & $\begin{array}{l}\text { MTsN } \\
\text { Piyungan }\end{array}$ & Sudah & BSA & $\mathrm{S} 1$ \\
\hline 24 & $\begin{array}{l}\text { Musa Surahman, } \\
\text { M.Pd.I }\end{array}$ & $\begin{array}{l}\text { MTsN } \\
\text { Piyungan }\end{array}$ & Sudah & PI & $\mathrm{S} 2$ \\
\hline 25 & Nurhadi, S.Ag & $\begin{array}{l}\text { MTsN } \\
\text { Sumberagung }\end{array}$ & Sudah & SKI & $\mathrm{S} 1$ \\
\hline 26 & $\begin{array}{l}\text { Purwadi } \\
\text { Pangestutyas }\end{array}$ & $\begin{array}{l}\text { MTs Ibnu } \\
\text { Qoyyim Putra }\end{array}$ & Belum & - & MA \\
\hline 27 & $\begin{array}{l}\text { Qowiyyul Aziz, } \\
\text { S.Pd }\end{array}$ & MTsN Lab UIN & Belum & PBI & $\mathrm{S} 1$ \\
\hline 28 & Seno, S.Pd.I & $\begin{array}{l}\text { MTs Muh. } \\
\text { Bambanglipuro }\end{array}$ & Belum & PAI & $\mathrm{S} 1$ \\
\hline 29 & $\begin{array}{l}\text { Siti Rodiah, } \\
\text { S.Pd.I }\end{array}$ & $\begin{array}{l}\text { MTsN Bantul } \\
\text { Kota }\end{array}$ & Sudah & PBA & $\mathrm{S} 1$ \\
\hline 30 & Sri Suharti, S.Ag & $\begin{array}{l}\text { MTsN } \\
\text { Gondowulung }\end{array}$ & Sudah & PBA & $\mathrm{S} 1$ \\
\hline 31 & $\begin{array}{l}\text { Drs. Subakir, } \\
\text { M.S.I }\end{array}$ & $\begin{array}{l}\text { MTs Ma'had } \\
\text { An Nur }\end{array}$ & Sudah & MKPI & $\mathrm{S} 2$ \\
\hline 32 & Suhadak, S.Ag & $\begin{array}{l}\text { MTs Ma'arif } \\
\text { Dlingo }\end{array}$ & Sudah & $\mathrm{AF}$ & $\mathrm{S} 1$ \\
\hline 33 & Sunariyah, S.Ag & $\begin{array}{l}\text { MTsN } \\
\text { Gondowulung }\end{array}$ & Sudah & PBA & $\mathrm{S} 1$ \\
\hline 34 & $\begin{array}{l}\text { Titiek Fathonah, } \\
\text { S.Ag }\end{array}$ & MTs Al-Furqon & Sudah & BAR & $\mathrm{S} 1$ \\
\hline 35 & Tutik Husniati & $\begin{array}{l}\text { MTsN Bantul } \\
\text { Kota }\end{array}$ & Sudah & PAI & $\mathrm{S} 1$ \\
\hline 36 & $\begin{array}{l}\text { Ummi Kultsum, } \\
\text { M.S.I }\end{array}$ & $\begin{array}{l}\text { MTsN } \\
\text { Wonokromo }\end{array}$ & Sudah & MKPI & $\mathrm{S} 2$ \\
\hline 37 & $\begin{array}{l}\text { Yulia Eka Z., } \\
\text { S.Pd.I }\end{array}$ & MTs Ma'arif & Belum & PAI & $\mathrm{S} 1$ \\
\hline
\end{tabular}


Tabel. 2

Jenis Kelamin Guru Bahasa Arab Madrasah Tsanawiyah

di Kabupaten Bantul

\begin{tabular}{|c|c|c|}
\hline No & Usia Guru & Jumlah Guru \\
\hline 1 & Laki-laki & 23 Guru \\
\hline 2 & Perempuan & 14 Guru \\
\hline
\end{tabular}

Tabel. 3

Data Usia Guru Bahasa Arab Madrasah Tsanawiyah di Kabupaten Bantul

\begin{tabular}{|c|c|c|}
\hline No & Usia Guru & Jumlah Guru \\
\hline 1 & 53 Tahun & 1 Guru \\
\hline 2 & 52 Tahun & 1 Guru \\
\hline 3 & 51 Tahun & 1 Guru \\
\hline 4 & 48 Tahun & 1 Guru \\
\hline 5 & 47 Tahun & 1 Guru \\
\hline 6 & 46 Tahun & 1 Guru \\
\hline 7 & 45 Tahun & 2 Guru \\
\hline 8 & 44 Tahun & 2 Guru \\
\hline 9 & 43 Tahun & 2 Guru \\
\hline 10 & 42 Tahun & 1 Guru \\
\hline 11 & 41 Tahun & 2 Guru \\
\hline 12 & 40 Tahun & 2 Guru \\
\hline 13 & 39 Tahun & 1 Guru \\
\hline 14 & 38 Tahun & 2 Guru \\
\hline 15 & 37 Tahun & 1 Guru \\
\hline 16 & 36 Tahun & 1 Guru \\
\hline 17 & 35 Tahun & 1 Guru \\
\hline 18 & 34 Tahun & 1 Guru \\
\hline 19 & 33 Tahun & 2 Guru \\
\hline 20 & 32 Tahun & 2 Guru \\
\hline 21 & 31 Tahun & 3 Guru \\
\hline 22 & 30 Tahun & 1 Guru \\
\hline 23 & 29 Tahun & 1 Guru \\
\hline 24 & 28 Tahun & 1 Guru \\
\hline 25 & 27 Tahun & 1 Guru \\
\hline 26 & 23 Tahun & 1 Guru \\
\hline 27 & 22 Tahun & 1 Guru \\
\hline
\end{tabular}


Tabel. 4

Data Pendidikan Berdasarkan Tingkat Pendidikan Guru Bahasa Arab

Madrasah Tsanawiyah di Kabupaten Bantul

\begin{tabular}{|c|c|c|}
\hline No & Tingkat Pendidikan & Jumlah Guru \\
\hline 1 & SLTA/SMA & 2 Guru \\
\hline 2 & D3 & 1 Guru \\
\hline 3 & S1 & 29 Guru \\
\hline 4 & S2 & 5 Guru \\
\hline
\end{tabular}

Tabel. 5

Data Pendidikan Berdasarkan Jurusan Pendidikan Guru Bahasa Arab

Madrasah Tsanawiyahdi Kabupaten Bantul

\begin{tabular}{|c|c|c|c|c|c|}
\hline No & Jurusan Pendidikan & Jenjang & $\begin{array}{c}\text { Jumlah } \\
\text { Guru }\end{array}$ & Jenjang & $\begin{array}{c}\text { Jumlah } \\
\text { Guru }\end{array}$ \\
\hline 1 & Pendidikan Bahasa Arab & S1/D3 & 15 & S2 & \\
\hline 2 & Bahasa Sastra Arab & S1/D3 & 3 & S2 & \\
\hline 3 & Pendidikan Agama Islam & S1/D3 & 9 & S2 & 2 \\
\hline 4 & Jurusan Lain & S1/D3 & 8 & S2 & 3 \\
\hline
\end{tabular}

Tabel. 6

Data Status Kepegawaian Guru Bahasa Arab Madrasah Tsanawiyah di Kabupaten Bantul

\begin{tabular}{|c|c|c|}
\hline No & Status Kepegawaian & Jumlah Guru \\
\hline 1 & PNS & 17 \\
\hline 2 & Non PNS & 20 \\
\hline 3 & Sudah Sertifikasi & 24 \\
\hline 4 & Belum Sertifikasi & 13 \\
\hline
\end{tabular}

\section{Hasil Tes Guru}

a. Guru yang Sudah Sertifikasi

Hasil tes guru yang sudah sertifikasi sebanyak 24 guru adalah sebagai berikut: 
Tabel.7

Hasil Tes Kompetensi Pedagogik Guru Bahasa Arab MTs yang sudah sertifikasi

\begin{tabular}{|c|l|l|c|}
\hline No & \multicolumn{1}{|c|}{ Nama Guru } & \multicolumn{1}{|c|}{ Tempat Tugas } & Nilai \\
\hline 1 & Musa Surahman, M.Pd.I & MTsN Piyungan & 96 \\
\hline 2 & Sri Suharti, S.Ag & MTsN Gondowulung & 90 \\
\hline 3 & Muhammad Jawis, S.S & MTsN Piyungan & 90 \\
\hline 4 & Miftakhul Munir, S.Ag & MTsN Griloyo & 85 \\
\hline 5 & Muh. Khoeron, S.Ag & MTsN Dlingo & 84 \\
\hline 6 & Titiek Fathonah, S.Ag & MTs Al-Furqon & 84 \\
\hline 7 & Kamiludin, S.Pd.I & MTs Muh.Kasihan & 83 \\
\hline 8 & Anis Suryani, S.Ag & MTsN Bantul Kota & 83 \\
\hline 9 & Ahmad Daris Mustofa & MTsN Wonokromo & 80 \\
\hline 10 & Tutik Husniati & MTsN Bantul Kota & 80 \\
\hline 11 & Dra. Istriyanti & MTsN Griloyo & 79 \\
\hline 12 & Drs. Amaroni & MTs Ali Maksum & 79 \\
\hline 13 & Sunariyah, S.Ag & MTsN Gondowulung & 78 \\
\hline 14 & Asfari, S.Ag & MTsN Lab UIN & 75 \\
\hline 15 & Siti Rodiah & MTsN Bantul Kota & 75 \\
\hline 16 & Imroatul Azizah, S.Ag & MTs Ali Maksum & 74 \\
\hline 17 & Nurhadi, S.Ag & MTsN Sumberagung & 73 \\
\hline 18 & Ummi Kultsum & MTsN Wonokromo & 73 \\
\hline 19 & Jumanudin, M.Pd.I & MTsN Pundong & 68 \\
\hline 20 & Drs. Subakir, M.S.I & MTs Ma'had An Nur & 63 \\
\hline 21 & Drs. Achmad Charis M. & MTsN Wonokromo & 53 \\
\hline 22 & Jarnawi, S.Ag & MTs Muh.Pepe & 53 \\
\hline 23 & Suhadak, S.Ag & MTs Ma'arif Dlingo & 49 \\
\hline 24 & M Marwan & MTs Al Falah Pandak & 15 \\
\hline
\end{tabular}

Dari data tersebut dapat kita peroleh sekor tetingginya adalah 96, nilai terendah adalah 15 , sedangkan meannya sebesar 73,42 dan standar deviasinya sebesar 17,14.

b. Guru yang Belum Sertifikasi

Hasil tes guru yang belum sertifikasi sebanyak 13 guru adalah sebagai berikut: 
Tabel.14

Hasil Tes Kompetensi Pedagogik Guru Bahasa Arab MTs yang belum sertifikasi

\begin{tabular}{|c|l|l|c|}
\hline No & \multicolumn{1}{|c|}{ Nama Guru } & \multicolumn{1}{|c|}{ Tempat Tugas } & Nilai \\
\hline 1 & Laila Maftuhah, S.Pd.I & MTs Hasyim Asy'ari & 88 \\
\hline 2 & Qowiyyul Aziz & MTsN Lab UIN & 83 \\
\hline 3 & Asna Fitriani, S.Pd.I & MTs Al Falaah Pandak & 80 \\
\hline 4 & Heru Sukamto, A.Md & MTs Muh. Sanden & 78 \\
\hline 5 & Seno, S.Pd.I & MTs Muh. Bambanglipuro & 74 \\
\hline 6 & Yulia Eka Zelviana & MTs Ma'arif Dlingo & 70 \\
\hline 7 & Janatul Mutmainah & MTs Al Mahalli & 68 \\
\hline 8 & Hendriana Wijaya & MTs Ibnu Qoyyim Putra & 68 \\
\hline 9 & Haryanto, S.Pd.I & MTs Ma'had Islamy & 64 \\
\hline 10 & Atik Malihah M & MTs Ibnu Qoyyim Putra & 48 \\
\hline 11 & Hafidl Hidayat, S.Fil.I & MTs Muh. Pepe & 45 \\
\hline 12 & Mahrus, S.Pd.I & MTs Ma'had An Nur & 44 \\
\hline 13 & Purwadi Pangestutyas & MTs Ibnu Qoyyim Putra & 31 \\
\hline
\end{tabular}

Dari data tersebut dapat kita peroleh sekor tetingginya adalah 88, nilai terendah adalah 31, sedangkan meannya sebesar 64,69 dan standar deviasinya sebesar 17,46 .

\section{Uji Hipotesis}

Dalam penelitian ini peneliti menggunakan teknik analisis kuantitatif yaitu menggunakan Test " $t$ " (" $t$ " Test) sebagai teknik analisisnya.

a. Uji Persyaratan Hipotesis

1). Uji Normalitas

Pada uji Komogorof-smirnov adalah 0,125 pada kelompok guru yang sudah sertifikasi dan 0,733 pada kelompok guru yang belum sertifikasi, karena kedua sig. Tersebut lebih besar dari 0,05 maka Ho diterima, artinya data nilai tes kelompok guru yang sudah sertifikasi dan kelompok guru yang belum sertifikasi berdistribusi normal.

2). Uji Homogenitas 
Pada uji One-Way Anova adalah 0,151, karena sig. tersebut lebih besar dari 0,05 maka Ho diterima, artinya data nilai tes kelompok guru yang sudah sertifikasi dan kelompok guru yang belum sertifikasi mempunyai varian yang sama (homogen).

b. Hasil Uji Hipotesis

Dari hasil pengujian Independent Sample Test, diperoleh $\mathrm{T}_{\text {hitung }}$ sebesar 1,469. Sedangkan $T_{\text {tabel }}$ dengan derajat kebebasan $(\mathrm{df})=35$ sebesar 2,03. Karena $\mathrm{T}_{\text {hitung }}$ lebih kecil dari $\mathrm{T}_{\text {tabel }}(1,469<2,03)$ dan Signifikansinya lebih besar dari signifikansi $0,05(0,005<0,05)$ maka Ho terima, artinya tidak ada perbedaan nilai tes yang signifikan antara kelompok guru yang sudah sertifikasi dengan kelompok guru yang belum sertifikasi. Pada tabel Group statistics diatas terlihat rata-rata (mean) untuk kelompok guru yang sudah sertifikasi adalah 73,42 dan untuk kelompok guru yang belum sertifikasi adalah 64,69, artinya bahwa nilai rata-rata kelompok guru yang sudah sertifikasi tidak lebih tinggi dari pada rata-rata untuk kelompok guru yang belum sertifikasi.

\section{KESIMPULAN}

Jika kita melihat nilai rata-rata dari hasil tes kompetensi Pedagogik Guru Bahasa Arab MTs dalam Merancang dan Melaksanakan Evaluasi Pembelajaran di Kabupaten Bantul, untuk guru yang sudah sertifikasi memiliki nilai rata-rata sebesar 73 dan untuk guru yang belum sertifikasi memiliki nilai rata-rata sebesar 65 , maka dengan berpedoman pada PAP skala lima diatas, peneliti menyatakan bahwa kompetensi Pedagogik Guru Bahasa Arab MTs dalam Merancang dan Melaksanakan Evaluasi Pembelajaran baik bagi guru yang sudah sertifikasi maupun belum sertifikasi, mempunyai tingkat kemampuan cukup.

Sedangkan jika kita lihat dari hasil pengujian Independent Sample Test, pada tabel diatas diperoleh $\mathrm{T}_{\text {hitung }}$ sebesar 1,469. Sedangkan $\mathrm{T}_{\text {tabel }}$ dengan derajat kebebasan $(\mathrm{df})=35$ sebesar 2,03. Karena $\mathrm{T}_{\text {hitung }}$ lebih kecil dari $\mathrm{T}_{\text {tabel }}$ 
$(1,469<2,03)$ dan Signifikansinya lebih besar dari signifikansi 0,05 $(0,005$ $<0,05)$ maka Ho terima, artinya tidak ada perbedaan nilai tes yang signifikan antara kelompok guru yang sudah sertifikasi dengan kelompok guru yang belum sertifikasi. Pada tabel Group statistics diatas terlihat rata-rata (mean) untuk kelompok guru yang sudah sertifikasi adalah 73,42 dan untuk kelompok guru yang belum sertifikasi adalah 64,69, artinya bahwa nilai ratarata kelompok guru yang sudah sertifikasi tidak lebih tinggi dari pada ratarata untuk kelompok guru yang belum sertifikasi.

Adapun kelengkapan administrasi guru bahasa Arab Madrasah Tsanawiyah di Kabupaten Bantul sudah cukup lengkap, namun masih ada beberapa administrasi yang masih jarang dimiliki oleh guru diantara adalah kartu soal, analisis SK/KD, bahan ajar berbasis ICT, jurnal/agenda guru dan penelitian tindak kelas.

Dari data Curriculum Vitae guru bahasa Arab Madrasah Tsanawiyah di Kabupaten Bantul, kita ketahui bahwa guru bahasa Arab yang memiliki latar belakang pendidikan Pendidik Bahasa Arab hanya 15 guru dari 37 guru yang ada, jika kita prosentasikan guru yang memiliki latar belakang pendidikan bahasa Arab hanya 40,5\% saja, hal itu bisa menjadi bukti bahwa masih kurangnya guru bahasa Arab yang memiliki latar belakang pendidikan bahasa Arab di Kabupaten Bantul. Walaupun itu belum tentu yang menjadi faktor kecilnya nilai-nilai UAMBN mata pelajaran di wilayah Kabupaten Bantul, namun hal itu juga sebaiknya menjadi perhatian pemerintah, agar pendidikan Bahasa Arab di wilayah Kabupaten Bantul lebih bermutu dan meningkat. 


\section{DAFTAR PUSTAKA}

Daryanto, Evaluasi Pendidikan, (Jakarta: PT Rineka Cipta, 2001), cet. II

Depdiknas RI, Standar Nasional Pendidikan (PP RI No. 19 Tahun 2005), (Jakarta: Sinar Grafika, 2006)

Djamarah, Syaiful Bahri, Prestasi Belajar dan Kompetensi Guru (Surabaya: UsahaNasional, 1994)

Echols, John M. dan Hasan Shadily, Kamus Inggris Indonesia, (Jakarta: Gramedia, 1996)

Hasil Ujian Akhir Madrasah Berstandar Nasional (UAMBN) Tahun Ajaran 20112012 dan Tahun Ajaran 2012-2013, http://yogyakarta.kemenag.go.id. Diakses 04 November 2013

Mulyasa E., Standar Kompetensi dan Sertifikasi Guru (Bandung: Remaja Rosdakarya, 2007)

.Peraturan Pemerintah Republik Indonesia No. 19 Tahun 2005 tentang Standar Nasional Pendidikan http://akademik.um.ac.id/wpcontent/uploads/2009/09/PP-NOMOR-19-TAHUN-2005.doc. Diakses 18 November 2013

Purwanto, Ngalim, Prinsip-Prinsip dan Teknik Evaluasi Pengajaran, (Bandung: PT Remaja Rosdakarya, 2006)

Sadullah, Uyo, Pedagogik (Ilmu Mendidik) (Bandung:Alfabeta, 2011)

Silverius, Suke, Evaluasi Hasil Belajar dan Umpan Balik, (Jakarta: PT Grasindo, 1991)

Sudjana, Nana, Penilaian Hasil Proses Belajar Mengajar, (Bandung: PT Remaja Rosdakarya 1991)

Usman, Moh. Uzer, Mejadi Guru Profesional, (Bandung : Remaja Rosdakarya, 2005)

Wahyuni, Sri, dan Abd. Syukur Ibrahim, Asesmen Pembelajaran Bahasa, (Bandung: PT. Refika Aditama, 2012) 